\title{
MONOPOLI IPA SEBAGAI MEDIA PEMBELAJARAN DI SMP/MTs KELAS VII PADA MATERI TATA SURYA
}

\author{
Shofroul Lailiyah \\ Program Studi Pendidikan IPA, FIP, Universitas Hasyim Asy’ari Tebuireng Jombang \\ shofroullailiyah5@gmail.com \\ Nur Kuswanti \\ Program Studi Pendidikan Biologi, FMIPA, Universitas Negeri Surabaya \\ nurkuswanti@unesa.ac.id
}

Lina Arifah Fitriyah

Program Studi Pendidikan IPA, FIP, Universitas Hasyim Asy'ari Tebuireng Jombang linaarifahfitriyah@gmail.com

\begin{abstract}
Abstrak
Pentingnya peran media dalam pembelajaran sehingga untuk tercapai suatu tujuan pembelajaran membutuhkan alat bantu yang dapat mempermudah siswa dalam menerima materi. Media edukatif yang dapat digunakan dalam pembelajaran dengan suasana menarik dan menyenangkan adalah monopoli..Tujuan penelitian ini adalah mengembangkan media pembelajaran monopoli IPA pada materi Tata Surya. Penelitian ini termasuk jenis pengembangan dengan menggunakan model ADDIE (Analyze, Design, Development, Implement, \& Evaluate). Keterbatasan penelitian ini adalah tahapan Implement tidak bisa dilaksanakan karena pandemi covid-19. Data diperoleh dengan menggunakan instrument pengumpulan data berupa penilaian kelayakan berdasarkan validitas dari ahli media, ahli materi dan guru IPA. Hasil penelitian ini menunjukkan bahwa media monopoli IPA pada materi Tata Surya dinyatakan validitas. Aspek validitas ditunjukkan dari hasil validasi monopoli IPA Tata Surya dan mendapat rata-rata skor 3,78 dengan kategori sangat valid.
\end{abstract}

Kata Kunci: Media Pembelajaran, Monopoli IPA, Tata Surya.

\begin{abstract}
The importance of the role of the media in learning so that to achieve a learning goal requires tools that can make it easier for students to receive material. Educational media that can be used in learning with an interesting and fun atmosphere is monopoly. The aim of this research is to develop a science monopoly learning media on the material of the Solar System. This research is a type of development using the ADDIE model (Analyze, Design, Development, Implement, \& Evaluate). The limitation of this study is that the Implement stage cannot be implemented due to the Covid-19 pandemic. The data were obtained using a data collection instrument in the form of a feasibility assessment based on the validity of the media expert, the material expert and the science teacher. The results of this study indicate that the natural science monopoly media on the material of the Solar System is declared valid. The validity aspect is shown from the results of the validation of the Solar System IPA monopoly and gets an average score of 3.78 in the very valid category.
\end{abstract}

Keywords: Learning Media, Science Monopoly, Solar System

\section{PENDAHULUAN}

Pendidikan adalah suatu usaha untuk menemukan potensi dalam diri setiap individu. Potensi tersebut dapat muncul melalui pengalaman belajar terprogram dalam bentuk pendidikan formal maupun nonformal. Melalui pendidikan tersebut siswa diharapkan dapat menjalankan peranan hidup secara tepat. Unsur-unsur pendidikan terdiri atas kurikulum, tujuan pendidikan, interaksi edukatif, pendidik, peserta didik dan lingkungan pendidikan (Triwiyanto, 2015: 23).

Belajar sebagai proses berpikir yang sangat kompleks yang diperlukan setiap individu guna mengoptimalkan tujuan 
pendidikannya (Mudlofir \& Rusydiyah, 2017:1). Pembelajaran bukan saja dilaksanakan di kelas dengan guru menerangkan dan siswa menyimak buku teks yang tebal dihadapannya. Inovasi dan kreasi dalam dunia pendidikan terus dilakukan oleh para ahli dan praktisi pendidikan guna mencapai tujuan pendidikan secara efisien. Efisiensi yang dimaksud ialah tujuan pendidikan tercapai secara maksimal dalam waktu pendek dan memanfaatkan sumber daya yang ada, tepat sasaran dan siswa ikut aktif dalam proses belajar tersebut.

Berdasarkan hasil observasi di kelas VII C SMP yang ada di Jombang pada tanggal 17 September 2019, menunjukkan bahwa metode yang sering digunakan guru mata pelajaran IPA adalah praktikum. Menurut siswa, guru menggunakan metode praktikum dengan persentase sebesar $52,38 \%$ dan metode pembelajaran secara berkelompok sebesar $30,95 \%$. Papan tulis sebagai media yang dipakai selama pembelajaran sebesar $75,67 \%$.

Hasil penyebaran angket juga menujukkan bahwa $70,58 \%$ siswa suka dengan penggunaan metode pembelajaran guru sebab melalui diskusi kelompok mereka dapat bekerjasama antar sesama teman. Kemudian $84,37 \%$ siswa menyukai pembelajaran secara berkelompok berbasis game untuk mendapatkan pengalaman belajar yang lebih menyenangkan, namun pembelajaran tersebut belum pernah diterima oleh siswa.

Pencapaian tujuan pembelajaran memerlukan alat bantu/media yang memudahkan siswa menerima materi. Pada kenyatannya penggunaan media yang tepat akan memberikan kesan pembelajaran yang bermakna sehingga tujuan pendidikan akan tercapai secara optimal. Pembelajaran IPA sering kali menggunakan alat dan bahan praktikum ada di laboratorium. Namun tidak semua materi IPA membutuhkan praktikum atau eksperimen. Sehingga ini menjadi salah satu alasan mengapa penggunaan media yang bervariasi dibutuhkan dalam pembelajaran.

Penelitian dalam bidang

pengembangan media pembelajaran selalu dinanti kehadirannya oleh praktisi pendidikan. Hal ini bertujuan sebagai referensi keefektifan dan kelayakan media tersebut untuk digunakan dalam pembelajaran. Peran dari media pembelajaran adalah memaksimalkan tingkat keberhasilan dan meminimalisir tingkat kegagalan dalam proses pembelajaran. Melalui penelitian akan ditemukan hal-hal baru yang menjadi akar permasalahan untuk kemudian dipecahkan melalui pemanfaatan media (Mudlofir dan Rusydiyah, 2017:239).

Berdasarkan data observasi peneliti akan mengembangkan media pembelajaran berupa Monopoli IPA yang telah diinovasi. Monopoli IPA adalah permainan edukatif yang menyenangkan dan dapat dimainkan dalam kelas klasikal. Permainan ini dikembangkan untuk mengenalkan konsep IPA pada materi tata surya yang dikemas dalam bentuk permainan edukatif. Media pembelajaran ini menjadi salah satu sarana untuk mendidik siswa agar berinvestasi secara cerdas untuk meraih prestasi yang akan dipergunakan setelah lulus nanti. Monopoli IPA juga akan dilengkapi dengan peraturan, hukuman dan penghargaan yang terletak pada 4 sudut monopoli dan titik tengah petak disetiap sisinya. Dalam permainan monopoli pada umumnya hal ini dikenal dengan istilah kesempatan, dana umum, penjara hanya lewat, bebas parkir, dan lain-lain.

Salah satu materi dalam mata pelajaran IPA adalah materi Tata Surya di kelas VII semester 2. Materi tata surya sebagai materi IPA yang tidak memerlukan proses menghitung atau praktikum di dalam laboratorium. Materi ini cenderung menuntut siswa untuk menghafal. Media monopoli IPA Tata Surya menjadi alternatif dalam proses pembelajaran untuk memudahkan siswa khususnya mereka yang lemah dibidang menghafal. Secara tidak langsung siswa akan termotivasi untuk membaca buku dan mencari jawaban pertanyaan dengan cepat. Ranah kognitif yang digunakan dalam media ini dibatasi pada ranah $\mathrm{C} 1$ dan $\mathrm{C} 2$ saja, dengan harapan siswa dapat menghafal materi dengan mudah. Apabila siswa menguasai ranah kognitif $\mathrm{C} 1$ (pengetahuan) dan $\mathrm{C} 2$ (pemahaman) maka akan lebih mudah bagi 
siswa untuk menguasai C3 dan C4. Sehingga C1 dan C2 ini menjadi dasar penting untuk dilanjutkan ke $\mathrm{C} 3$ dan $\mathrm{C} 4$.

Hasil penelitian relevan terkait penggunaan media pembelajaran monopoli ialah hasil penelitian Cahyaningrum (2014:63) memaparkan dalam hasil pengembangan monopoli smart science berbasis pendekatan saintifik pada siswa SMP dinyatakan valid dengan skor 4,02 dan minat belajar siswa dikatakan sangat baik dengan persentase $92,1 \%$. Hasil belajar siswa juga dikatakan sangat baik melalui hasil post-test dengan rata- rata nilai 87,57.

Penelitian relevan lainnya terkait pengembangan media pembelajaran oleh Rosyida (2017: 74) yaitu komik IPA kelas VIII SMP/MTs pada materi cahaya dan alat optik menunjukkan bahwa validasi materi mendapat skor 3,76 dan 3,67 untuk validasi media. Kepraktisan media diukur berdasarkan skor rata-rata dalam pembelajaran yaitu 94 dan respon siswa termasuk dalam kategori sangat praktis dengan persentase $92 \%$. Keefektifan media juga diukur berdasarkan nilai posttest siswa dengan skor ketuntasan $73 \%$ yang menyatakan bahwa media komik yang dikembangkan efektif. Penelitian ini bertujuan untuk mengembangkan monopoli IPA sebagai Media Pembelajaran di SMP/MTs Kelas VII Pada Materi Tata Surya.

\section{METODE}

Penelitian ini termasuk jenis pengembangan dengan menggunakan model ADDIE (Analyze, Design, Development, Implement, \& Evaluate). Keterbatasan penelitian ini adalah tahapan Implement tidak bisa dilaksanakan. Alur pengembangan ini dipaparkan pada Gambar 1 berikut:

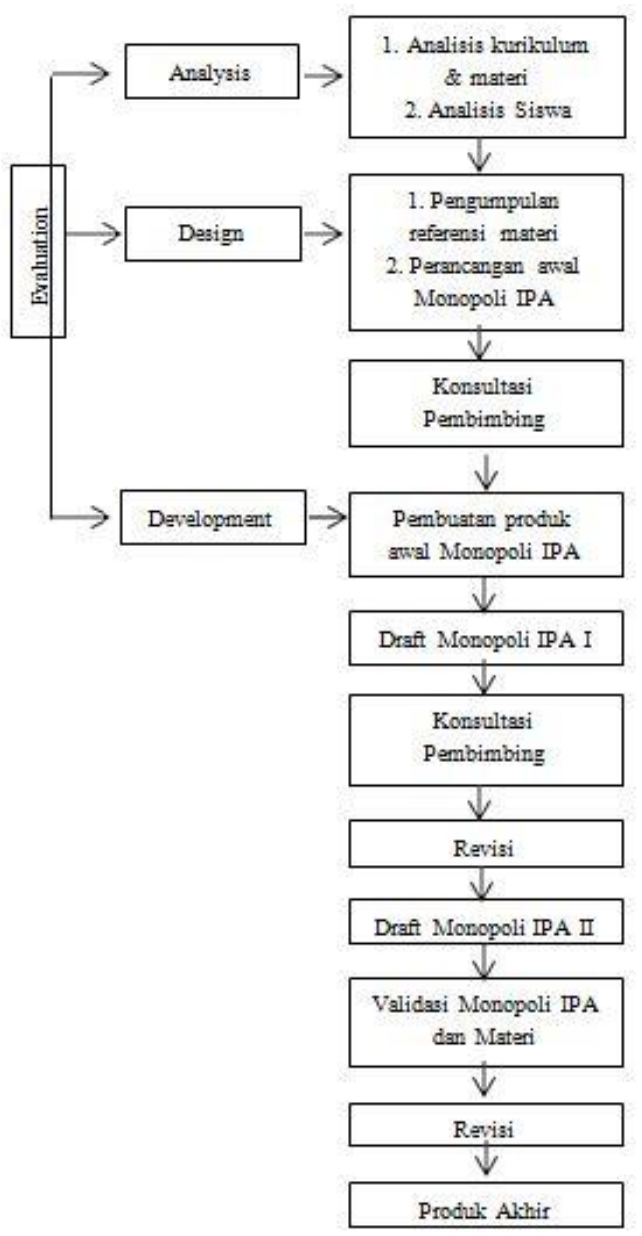

Gambar 1. Diagram Alir Langkah-Langkah Penelitian (Modifikasi dari Tegeh dkk, 2014:41) 
Tahap pertama dari penelitian dan pengembangan ini adalah menganalisis kurikulum dan materi serta menganalisis siswa. Kurikulum yang diterapkan dalam pengembangan ini adalah kurikulum 2013 revisi 2017 sehingga aspek yang dianalisis adalah kompetensi inti (KI) dan Kompetensi dasar (KD) yang kemudian diturunkan menjadi indikator dan tujuan pembelajaran. Indikator pembelajaran yang digunakan adalah: (1) Menjelaskan sistem tata surya; (2) Mendeskripsikan aspekaspek yang berkaitan dengan komponen penyusun tata surya; (3) Menentukan benda langit penyusun tata surya berdasarkan ciricirinya; (4) Mendeskripsikan gerak rotasi bumi dan aspek yang berkaitan; (5) Mendeskripsikan gerak revolusi Bumi dan aspek yang berkaitan; (6) Membedakan peristiwa yang terjadi akibat gerak rotasi dan revolusi bumi.

Aspek dalam diri siswa yang perlu dianalisis adalah perbedaan tingkat kemampuan, pengalaman belajar, dan usia. Hasil analisis ini sebagai pola dasar dalam pengembangan media monopoli IPA ini terkait pengembangan instrument yang akan dimuat dalam media, prosedur permainan, juga penilaian.

Tahap kedua adalah desain pengembangan produk yang dilakukan dengan mengumpulkan referensi mengenai materi Tata Surya SMP/MTs kelas VII pada semester 2, membuat rancangan monopoli IPA berdasarkan tujuan dan indikator pembelajaran dibuat dan mengkonsultasikan desain pengembangan produk kepada dosen pembimbing dan siap untuk pembuatan produk tahap awal.

Tahap ketiga adalah pengembangan produk yang dilakukan dengan: (1) pembuatan alas monopoli dengan menggunakan kertas manila dan kertas berwarna, menentukan posisi petak berisi pertanyaan, kesempatan, dana umum kemudian memasukkan pertanyaanpertanyaan dalam kantong; (2) Pengembangan bentuk permainan monopoli dengan memberikan perintah yang berbedabeda di setiap sudutnya; (3) Pembuatan pertanyaan yang kana diletakkan pada kantong monopoli.. Pertanyaan ini akan dibuat berdasarkan ranah kognitif $\mathrm{C} 1$ dan
C2; (4) Validasi draft monopoli IP oleh dosen ahli untuk merevisi produk.

Tahapan terakhir yaitu evaluasi Evaluasi dilakukan pada setiap tahapan agar proses penyempurnaan media pembelajaran monopoli IPA materi Tata Surya berdasarkan saran validator. Penghitungan penilaian dari validator menggunakan rumus:

skor rata - rata $=\frac{\text { total skor dari validator }}{\text { jumlah validator }}$

Perhitungan rata-rata skor hasil validasi akan diinterpretasikan dalam Tabel 1 berikut:

Tabel 1. Kriteria Interpretasi Skor Hasil Validas

\begin{tabular}{|l|l|}
\hline Skor Rata-Rata & Kriteria \\
\hline $0,00 \leq x \leq 1,75$ & Kurang Valid \\
\hline $1,75<x \leq 2,50$ & Cukup Valid \\
\hline $2,50<x \leq 3,50$ & Valid \\
\hline $3,50<x \leq 4,00$ & Sangat Valid \\
\hline
\end{tabular}

$\mathrm{x}$ : skor validasi ahli

Sumber: modifikasi dari Riduwan (2016) dalam Rosyida (2017:41)

Berdasarkan analisis validasi di atas, monopoli IPA dinyatakan valid dengan skor yang diperoleh $>2,50$.

\section{HASIL DAN PEMBAHASAN}

Hasil pengembangan ini monopoli IPA pada materi Tata Surya kelas VII untuk jenjang SMP/MTs. Pengembangan monopoli menggunakan ADDIE. Namun dari lima tahap model pengembangan yang diterapkan hanya tahap implementation tidak dapat dilaksanakan karena pandemi covid-19.

Pada tahap analisis materi, guru menerangkan bahwa salah satu materi yang belum bisa dilaksanakan dengan konsep student centered learning ialah materi Tata Surya. Kendala itu dikarenakan materi Tata Surya didominasi dengan teori yang harus dihafal oleh siswa yang tidak memungkinkan dilakukannya praktikum untuk membuktikan suatu fenomena. Materi Tata Surya yang perlu dibahas diantaranya; sistem tata surya, aspek-aspek yang berkaitan dengan komponen penyusun tata surya, menentukan benda 
langit berdasarkan ciri- cirinya, gerak rotasi dan revolusi bumi serta perihal terjadinya gerak rotasi dan revolusi bumi. Berdasarkan hal tersebut, peneliti memilih materi Tata Surya untuk dikembangkan medianya yaitu media pembelajaran dengan konsep permainan edukatif berupa monopoli IPA.

Kegiatan perencanaan yaitu mengumpulkan referensi materi dan membuat desain awal monopoli IPA. Materi yang akan digunakan adalah materi Tata Surya. Proses pengumpulan materi dimulai dengan mengumpulkan referensi pada buku paket IPA kelas VII SMP untuk mengetahui indikator apa saja yang harus tercapai dalam pembelajaran. Kemudian, tidak semua materi yang berhubungan dengan tata surya akan digunakan dalam pengembangan media pembelajaran ini. Peneliti akan membatasi materi ini menjadi 4 sub bab, yaitu sistem tata surya, (2) karakteristik komponen penyusun tata surya, (3) rotasi bumi, dan (4) revolusi bumi.

Pembuatan desain dilakukan dengan mengumpulkan referensi yang berkaitan dengan media pembelajaran monopoli IPA. Peneliti terlebih dahulu membuat sketsa kerangka papan monopoli melalui aplikasi canva yang kemudian dikonsultasikan kepada pembimbing untuk direvisi.

Proses pengembangan dibagi kedalam 3 draft. Draft I media pembelajaran monopoli dapat dilihat pada Gambar 2 berikut.

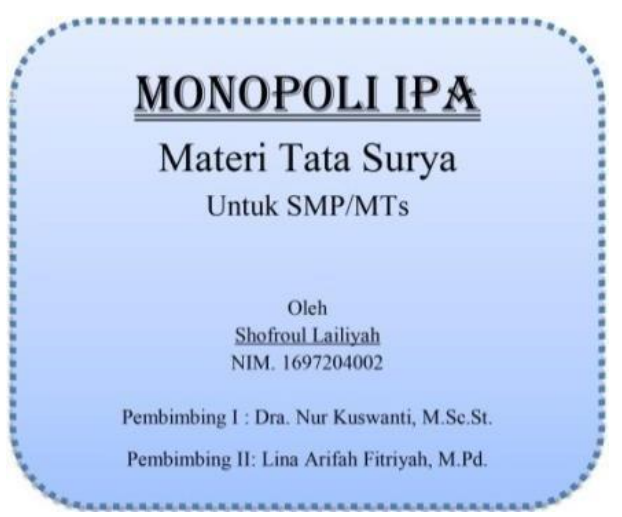

a) Cover Box Monopoli IPA

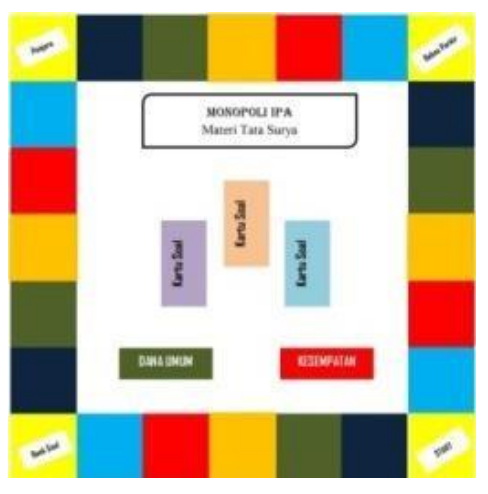

b) Tampilan Papan Monopoli IPA

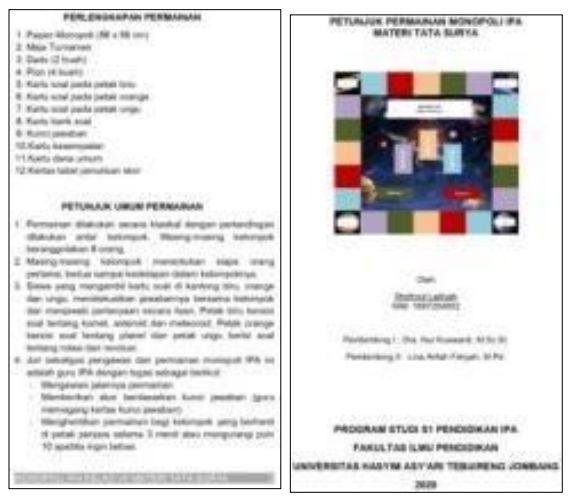

c) Petunjuk Penggunaan

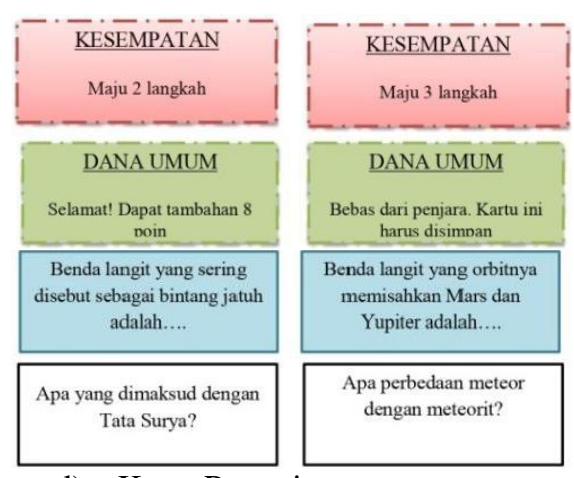

d) Kartu Permainan

Gambar 2. Draft I Media Pembelajaran Monopoli IPA

Satu set media pembelajaran monopoli IPA ini dilengkapi dengan perlengkapan permainan dengan daftar sebagai berikut: (1) kemasan box, (2) papan permainan monopoli IPA, (3) set kartu soal, bak soal, dana umum, dan kartu kesempatan, (4) dadu dan pion, (5) lembar indikator dan tujuan pembelajaran, lembar petunjuk umum permainan, lembar langkah permainan, lembar penulisan poin dan lembar kunci jawaban. 
Selanjutnya, draft I media pembelajaran monopoli IPA direvisi secara keseluruhan sesuai saran dan masukan dari dosen pembimbing. Dari revisi tersebut dihasilkan draft II dapat dilihat pada Gambar 3 berikut.

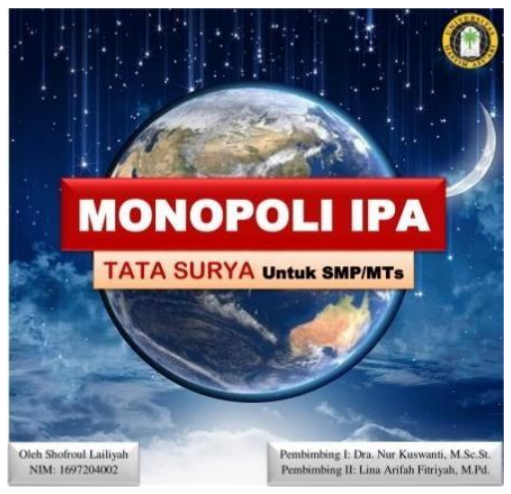

a) Cover Box Monopoli IPA

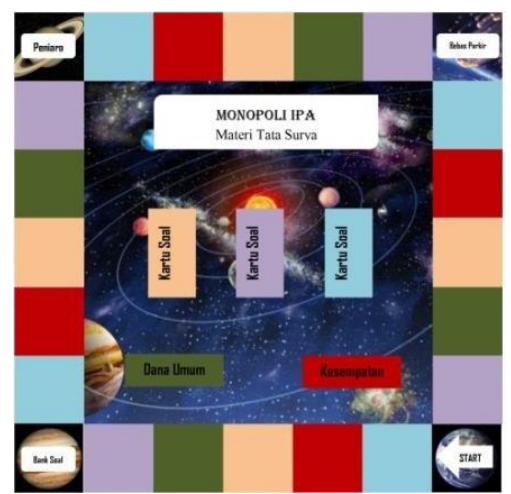

b) Tampilan Papan Monopoli IPA

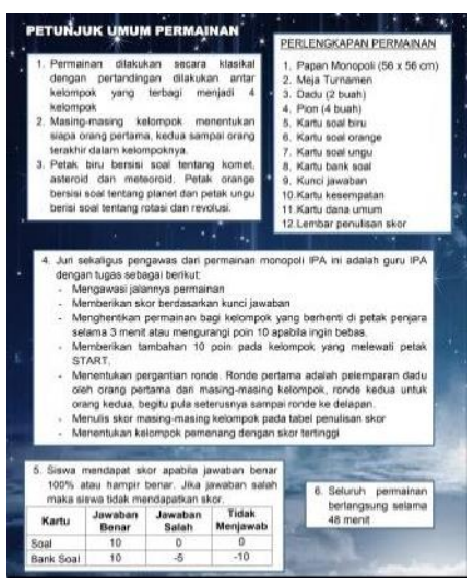

c) Petunjuk Penggunaan

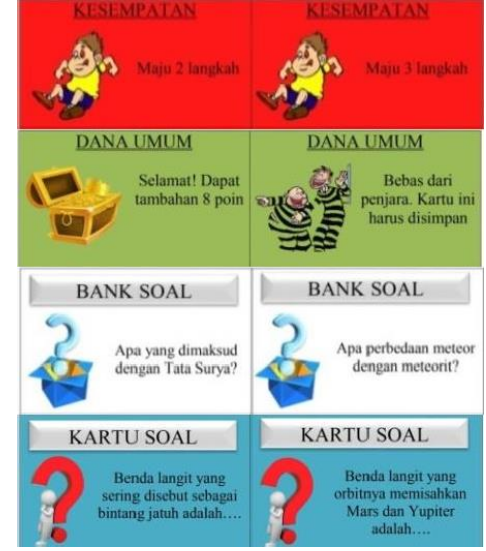

d) Kartu Permainan

Gambar 3. Draft II Media Pembelajaran Monopoli IPA

Selanjutnya, draft II media pembelajaran monopoli IPA yang telah divalidasi direvisi secara keseluruhan sesuai saran dan masukan dari validator. Dari revisi tersebut dihasilkan draft III media pembelajaran monopoli IPA yang dapat dilihat pada Gambar 4 berikut.

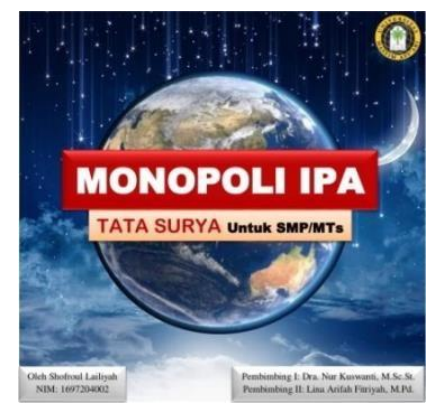

a) Cover Box Monopoli IPA

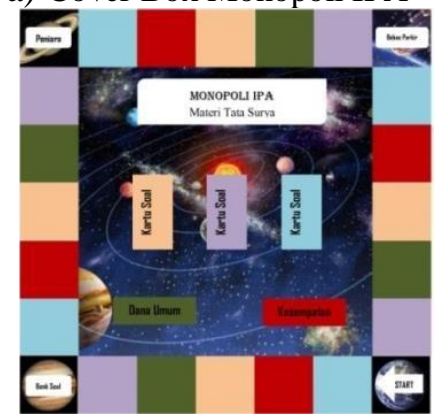

b) Tampilan Papan Monopoli IPA 


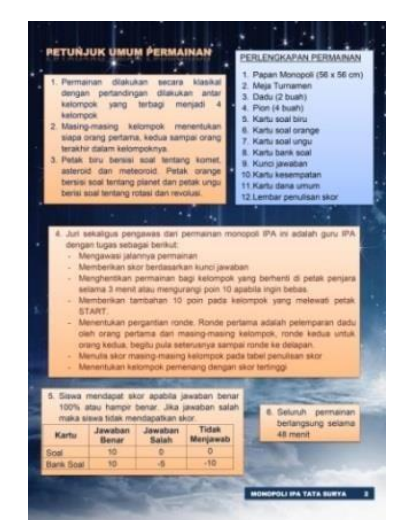

c) Petunjuk Penggunaan

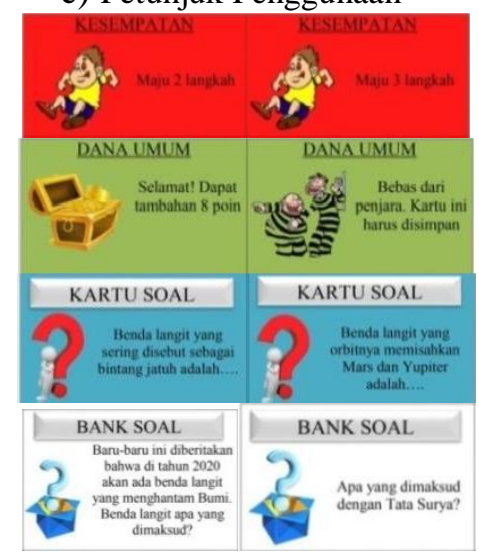

d) Kartu Permainan

Gambar 4. Draft III Media Pembelajaran Monopoli IPA

Rekapitulasi hasil validasi disajikan pada Tabel 2 berikut.

Tabel 2. Rekapitulasi Hasil Validasi Media Pembelajaran Monopoli IPA

\begin{tabular}{|l|c|l|}
\hline \multicolumn{1}{|c|}{$\begin{array}{c}\text { Aspek yang } \\
\text { divalidasi }\end{array}$} & Skor & Kategori \\
\hline $\begin{array}{l}\text { Pertanyaan dalam } \\
\text { Media Monopoli }\end{array}$ & 3,33 & Sangat Valid \\
\hline Kunci Jawaban & 4,00 & Sangat Valid \\
\hline Kebahasaan & 4,00 & Sangat Valid \\
\hline Pembelajaran & 3,66 & Sangat Valid \\
\hline Kemudahan & 3,33 & Sangat Valid \\
\hline Petunjuk Umum & 4,00 & Sangat Valid \\
\hline Langkah Permainan & 4,00 & Sangat Valid \\
\hline Kartu Permainan & 4,00 & Sangat Valid \\
\hline $\begin{array}{l}\text { Perlengkapan } \\
\text { Permainan }\end{array}$ & 4,00 & Sangat Valid \\
\hline Komunikasi Visual & 4,00 & Sangat Valid \\
\hline $\begin{array}{l}\text { Tampilan } \\
\text { Menyeluruh }\end{array}$ & 4,00 & Sangat Valid \\
\hline Gambar & 3,66 & Sangat Valid \\
\hline Pemilihan Bahan & 3,33 & Valid \\
\hline Penulisan & 3,66 & Sangat Valid \\
\hline Rata-Rata Skor & $\mathbf{3 , 7 8}$ & Sangat Valid \\
\hline
\end{tabular}

\section{Keterangan:}

$$
\begin{aligned}
& 1,00 \leq x \geq 1,75=\text { Kurang } \\
& \text { Valid } 1,76 \leq x \geq 2,50=\text { Cukup } \\
& \text { Valid } 2,51 \leq x \geq 3,25=\text { Valid } \\
& 3,26 \leq x \geq 4,00=\text { Sangat Valid }
\end{aligned}
$$

Isnaini (206: 130) menjelaskan bahwa satu aspek yang diukur dalam proses validasi adalah kesesuaian materi dengan kompetensi dasar. Sehingga kompetensi dasar perlu dicantumkan dalam media pembelajaran. Saran dari validator yaitu mengubah warna tulisan dalam petunjuk permainan menjadi warna yang lebih mencolok agar terlihat lebih menarik. Produk dalam pembelajaran yang dinyatakan valid maka selanjutnya akan layak digunakan dalam kegiatan pembelajaran. Kelayakan berdasarkan validasi suatu produk pengembangan harus memenuhi kriteria dari aspek isi yaitu suatu produk pengembangan dalam pembelajarannya harus berdasarkan kompetensi. Selain itu harus memenuhi dari aspek konstruksi yaitu produk yang dikembangkan harus tersusun baik dan tepat sepadan dengan tingkat perkembangan peserta didik. Produk yang dihasilkan dari pengembangan tersebut juga harus memenuhi aspek penggunaan bahasa harus gampang dipahami dengan menggunakan bahasa baku (EYD) (Fitriyah \& Wardana, 2019).

\section{SIMPULAN}

Berdasarkan hasil penelitian yang telah dilakukan maka dapat disimpulkan sebagai berikut: (1) Penelitian pengembangan ini menghasilkan produk berupa media pembelajaran monopoli IPA untuk materi tata surya. Proses pengembangan menghasilkan tiga draft media pembelajaran monopoli IPA yang telah mendapatkan saran dan masukan dari dosen pembimbing, dosen ahli media, dosen ahli materi dan guru IPA. (2) Produk media pembelajaran monopoli IPA materi tata surya telah dikembangkan sesuai dengan empat prosedur pada model pengembangan ADDIE yang meliputi tahap analisis, tahap perencanaan tahap pengembangan dan tahap evaluasi. (3) Kualitas media pembelajaran monopoli 
IPA dinyatakan sangat valid sebagai media pembelajaran pada materi tata surya kelas

\section{DAFTAR PUSTAKA}

Fitriyah, L. A., \& Wardana, H. K. (2019). Profil Lembar Kerja Peserta Didik (LKPD) Unsur, Senyawa, Dan Campuran Dengan Pendekatan Stem. Jurnal Zarah, 7(2), 86-92.

Isnaini, Annisa Nur. 2016. Pengembangan Media Pembelajaran Monopoli Akuntansi untuk Meningkatkan Motivasi belajar Siswa Kelas X AK 2 SMK Negeri 4 Klaten Tahun Ajaran 2015/2016. Skripsi. Dipublikasikan Universitas Negeri Yogyakarta.
VII berdasarkan penilaian dari tiga validator dengan rata-rata skor 3,78.

Mudlofir, Ali dan Rusydiyah, Evi Fatimatur. 2017. Desain Pembelajaran Inovatif. Jakarta: PT Rajagrafindo Persada.

Rosyida, Latifatur. 2017. Pengembangan Komik IPA Sebagai Media Pembelajaran di SMP/MTs Kelas VIII Materi Cahaya dan Alat Optik. Skripsi. Tidak Dipublikasikan. Universitas Hasyim Asy'ari.

Tegeh, Made dkk. 2014. Model Penelitian Pengembangan. Yogyakarta: Graha Ilmu.

Triwiyanto, Teguh. 2015. Pengantar Pendidikan. Jakarta: PT Bumi Aksara. 